\title{
BMJ Open Emergency volunteering willingness and participation: a cross-sectional survey of residents in northern China
}

\author{
Mengli Shi, ${ }^{1}$ Wei Xu, ${ }^{1}$ Lijun Gao, ${ }^{1,2}$ Zheng Kang, ${ }^{1,2}$ Ning Ning, ${ }^{1,2}$ Chaojie Liu, ${ }^{3}$ \\ Chao Liang, ${ }^{1}$ Hong Sun, ${ }^{1,2}$ Mingli Jiao, ${ }^{1,2}$ Libo Liang, ${ }^{1,2}$ Ye Li, ${ }^{1,2}$ Yu Cui, ${ }^{1,2}$ \\ Xiaowen Zhao, ${ }^{1}$ Jie Fei, ${ }^{1}$ Qiuyu Wei, ${ }^{1}$ Ming Yi, ${ }^{1}$ Yanhua Hao, ${ }^{1,2}$ Qunhong $\mathrm{Wu}^{1,2}$
}

To cite: Shi M, Xu W, Gao L, et al. Emergency volunteering willingness and participation: a crosssectional survey of residents in northern China. BMJ Open 2018;8:e20218. doi:10.1136/ bmjopen-2017-020218

- Prepublication history for this paper is available online. To view these files please visit the journal online (http://dx.doi. org/10.1136/bmjopen-2017020218).

YH and QW contributed equally.

Received 25 0ctober 2017

Revised 17 April 2018

Accepted 7 June 2018

Check for updates

C Author(s) (or their employer(s)) 2018. Re-use permitted under CC BY-NC. No commercial re-use. See rights and permissions. Published by BMJ.

${ }^{1}$ School of Health Management, Harbin Medical University, Harbin, China

${ }^{2}$ Department of Social Medicine, Collaborative Innovation Center of Social Risks Governance in Health, Harbin, China

${ }^{3}$ School of Psychology and Public Health, La Trobe University, Bundoora, Victoria, Australia

\section{Correspondence to}

Professor Yanhua Hao;

hyhyjw@126.com and Professor

Qunhong Wu;

wuqunhong@163.com

\section{ABSTRACT}

Objectives This study aimed to identify factors that influence people's willingness to volunteer and participation in emergency volunteering in northern China. Design/Setting This study was conducted in Heilongjiang province in September and October 2014 using a mixed methods approach, which included a crosssectional questionnaire survey on community residents and in-depth interviews with community residents and relevant organisational managers and officials in relation to emergency responses. A stratified cluster sampling strategy was employed to select questionnaire respondents.

Participants 2686 respondents completed the questionnaire survey; 19 key informants were interviewed. Primary and secondary outcome measures Willingness to volunteer was the major concern of this study. Selfreported past experience of the participants in emergency volunteering served as a secondary outcome.

Results $65.7 \%$ of respondents were willing to volunteer in emergencies. $24.3 \%$ of respondents had participated in emergency actions. Higher levels of willingness to volunteer and participation in volunteering were found in those who resided in rural areas $(\mathrm{OR}=1.308$ (1.064 to 1.608 ) for willingness; $0 R=1.518$ (1.208 to 1.908 ) for participation), had stronger community attachment ( $O R=1.720$ (1.429 to 2.069) for willingness; $0 R=1.547$ (1.266 to 1.890) for participation), had higher recognition of responsibility $(\mathrm{OR}=1.981$ (1.498 to 2.619$)$ for willingness; $\mathrm{OR}=1.517$ (1.177 to 1.955) for participation), demonstrated preparedness behaviour ( $\mathrm{OR}=1.714$ (1.424 to 2.064) for willingness; $\mathrm{OR}=1.391$ (1.151 to 1.681) for participation) and were covered by injury insurance ( $O R=1.335$ (1.102 to 1.619) for willingness; $O R=1.822$ (1.500 to 2.214) for participation). The in-depth interviews revealed that an inappropriate policy environment and poo volunteer organisational management were major barriers for converting willingness into actions.

Conclusion A relatively high level of willingness to volunteer in emergencies in northern China is associated with a range of individual, community and institutional factors. Efforts should be made to translate willingness into effective contributions to the emergency response system. This can be done through improving policies, regulations, coordination mechanisms and volunteer training and support.

\section{Strengths and limitations of this study}

- This study adopted a mixed methods approach, involving a questionnaire survey and in-depth interviews.

- The sample size is large, enabling us to explore determinants of emergency volunteering from individual, community and institutional perspectives.

- The concept of 'emergency events' adopted in this study was general and covered a broad range of events, which may lead to vague or uncertain answers from some respondents.

- Self-reported willingness to volunteer varied with different scenarios.

- This study was conducted in Heilongjiang, which may not be representative of the entire country of China.

\section{INTRODUCTION}

Emergency volunteering emerged and developed in a time of crisis. Since the second half of the 20th century, the world has encountered a high incidence of disastrous events: 1986 Chernobyl disaster in Ukraine, '9.11' terrorist attack in 2001 in the USA, 2003 SARS crisis, 2008 Wenchuan earthquake in China, just to name a few. Some of the disastrous events are natural disasters, others are manmade. It is undeniable that governments play a leading role in emergency responses. However, in many cases, the emergency response needs exceed the capacity of government agencies and professional rescue bodies. Volunteers often play a critical role across the entire spectrum of rescue efforts. ${ }^{1}$ For example, immediately following the 1995 Oklahoma city bombing, voluntary organisations and civilian volunteers participated in the search and rescue efforts and a Compassion Centre was established by volunteers within 7 hours. $^{2}$ After the 1976 Tangshan earthquake, survivors formed rescue teams immediately to save people buried in the debris. ${ }^{3}$ Indeed, without the efforts of spontaneous volunteers, 
immediate response and recovery would not have a high success rate. ${ }^{4}$

The best definition of volunteers was probably given during the International Year of Volunteers (2001): 'A volunteer is a person, who, having carried out the duties of every citizen, places her/his own capacity at the disposal of others, for the community or for all humanity. She/ he operates in a free and gratuitous manner promoting creative and effective responses to the needs of beneficiaries of her/his own action and contributing to the realisation of common goods'. ${ }^{5}$ There are three types of volunteers in emergency responses according to the Hong Kong Red Cross: a community-based volunteer is someone who comes from the community and is willing to help others; a functional volunteer is someone who is equipped with specific emergency skills, such as first aid and psychological support; a professional volunteer is someone who has a professional qualification, such as a doctor or nurse. ${ }^{6}$ Emergency volunteering requires a will to help others and also professional knowledge and skills. ${ }^{6}$

Some countries have attached great importance to improving the public capability of an emergency response. For example, in the USA, the Community Emergency Response Team (CERT) programme offers a consistent and nationwide approach to volunteer training, which has enhanced the public capability to respond to and recover from disasters. ${ }^{7}$ The Japanese government has integrated emergency education into school education and community activities and established multiple 'disaster prevention days' to carry out emergency training and exercises. ${ }^{8}$ Such regular emergency training ensures that people with qualified skills can be effectively deployed to emergency volunteer services during disasters. However, China has not yet established a regular community-based emergency training programme and lacks volunteers with specific knowledge and skills to respond to emergencies. ${ }^{9}$ These shortfalls were conspicuously exposed after the Wenchuan earthquake, even resulting in a "new victims' phenomenon: many volunteers had no capacity to provide rescue services and instead put themselves in a dangerous situation requiring support from others. ${ }^{9}$

The development of an organised emergency volunteer system in China is still in its infant stage. During the 2003 SARS outbreak, only a small number of social organisations and individuals provided volunteer services. The demand for large numbers of rescue workers in the 2008 Wenchuan earthquake accelerated the development of organised emergency volunteering. According to the statistics, more than 4 million volunteers (including both spontaneous and organised volunteers) were involved in disaster relief activities during the Wenchuan earthquake, which remained the largest emergency volunteering effort in China up to now. ${ }^{10}$ However, most of those volunteers were spontaneous and operated in an unorganised state, which even added some obstacles to the emergency rescue work (such as unintended interference with professional activities and the aforementioned 'new victims' phenomenon). ${ }^{9}$
There have been increasing calls to integrate volunteer organisations into the formal emergency response system. ${ }^{11}$ Many developed countries have established institutionalised mechanisms to attract, train and retain volunteers. ${ }^{12}$ In Japan, a volunteer centre was established, serving as a volunteer recruitment platform. ${ }^{13}$ In the USA, the Medical Reserve Corps is a national network of volunteers which maintains a recruitment and registration system for emergency volunteering. ${ }^{14}$ Formal volunteer organisations were also established in Germany, the UK and Australia. ${ }^{11}{ }^{15}$ In the case of emergencies, these organised volunteers can be mobilised and deployed rapidly. Such systems also offer appropriate protections on the health of the volunteers through training, support and insurance coverage. ${ }^{1416-18}$

In countries with a well-established volunteer system (comprising relevant laws, policies, organisations, advocacy mechanisms and training and deployment mechanisms), participation in volunteering is high. In the USA, for example, $40 \%$ of the total population is involved in volunteer services. ${ }^{19}$ Germany only has a population of about 82 million, but 23 million have participated in volunteer activities and 1.8 million have provided emergency volunteering services. ${ }^{15}$ It is not clear how many people in China are willing to volunteer and have actually provided emergency volunteer services. Due to the lack of a well-organised volunteer management system in China, only $1 \%$ of the total population has registered for volunteering services. ${ }^{19}$

The theory of rational action states that individual behaviours are influenced by their cognitions and attitudes based on the comprehensive consideration of various information. ${ }^{20}$ Extensive studies have been undertaken in western countries with regard to the motivation and benefits of volunteering. Willingness to volunteer often depends on specific circumstances ${ }^{21}$ and is also subject to the impacts of regulations and training. ${ }^{22-26}$ Finkelstein $e t a l^{25}$ categorised the motivation of volunteers into selfless and altruistic motives; self-interest (eg, career-related benefits) and social objectives (such as prosocial behaviours). Blau et $a t^{26}$ investigated the influence of incentive mechanisms on emergency volunteering and found that the desire for advancement opportunity and better pay is a strong reason for providing emergency volunteer services. However, there is a dearth of literature in China probing willingness to emergency volunteer and participation in emergency volunteering. This study aimed to fill the literature gap and provide evidence for policy development in relation to emergency volunteering (including both spontaneous and organised volunteering).

\section{METHODS}

\section{Questionnaire survey}

Study population

A cross-sectional questionnaire survey was conducted in Heilongjiang province in September and October 2014. Heilongjiang is located in the northeast of China, with a 
population over 38 million. The gross domestic product per capita in Heilongjiang reached $¥ 39352$ (US\$5700) in 2015, lower than the national average of $¥ 49730$ (US\$7957). ${ }^{27}$ Over the past few decades, this region experienced forest fires, floods, SARS and other disastrous events.

A multistage stratified cluster sampling strategy was adopted to ensure the demographic and social-economic diversity of the study participants. Five (out of 13) municipalities in Heilongjiang were selected: Harbin (capital city), Qiqihar, Mudanjiang, Jiamusi and Daqing. In each municipality, one urban district and one rural county were randomly selected. Two communities/villages were then randomly selected from each district/county. All of the households in the selected communities/villages were eligible to participate in the survey. Trained interviewers visited the selected households and explained the purpose of the survey to the person they met first, and then asked this person to nominate one adult member to complete the questionnaire. A total of 2800 questionnaires were returned, of which $2686(95.9 \%)$ were valid for data analyses.

The questionnaire survey was administered through face-to-face interviews. Each interview took about $20 \mathrm{~min}$. The interviewers were recruited from the postgraduate students in the School of Public Health at Harbin Medical University. They had attended a training workshop prior to embarking on the fieldwork. One experienced researcher was allocated to each community/village to supervise the data collection activities.

\section{Dependent variable}

Willingness to emergency volunteer: respondents were asked to rate on a 5-point Likert scale (ranging from 1 'no, not at all' to 5 'yes, very much') in relation to the question: 'Are you willing to respond to emergencies as a volunteer?'

Participation in emergency volunteering: respondents were asked whether they had ever participated in emergencies as a volunteer (yes or no).

\section{Independent variable}

The independent variables tested in this study included sociodemographic characteristics, awareness and attitudes towards emergency risks, community attachment, recognition of responsibility and self-efficacy in an emergency response. These variables were selected based on the existing literature. Rosychuk and colleagues suggest the application of the knowledge-attitudes-behaviour model in emergency volunteering studies, ${ }^{23}$ based on the theory of rational action. ${ }^{20}$ Enders recommends the addition of past experience and self-efficacy into the knowledge-attitudes-behaviour model. ${ }^{28}$ The self-efficacy theory posits that confidence and ability contribute to the individual's capacity to control their behaviours. ${ }^{29}$ In recent years, the social capital theory has started to attract increasing attention. Catts and Chamings proposed that social capital based on trust is critical to the effective functioning of volunteering. ${ }^{30}$
The sociodemographic characteristics of the respondents were measured by gender, age, residency, educational attainment and household income.

Knowledge: 18 statements (involving earthquake, fire, infectious disease, food poisoning and first aid) were designed to test the knowledge of the respondents in regard to emergencies. Respondents chose one of the answers for each statement: agree, disagree, don't know. A correct answer attracted a score of 1 , otherwise 0 .

Risk perception: respondents were asked to rate the risk of emergencies (four items) in relation to natural disaster (earthquake, flood), accidents (fire, road accident), public health (infectious disease, food poisoning) and social unrest (violence, terrorism), respectively, on a five-point Likert scale (ranging from 1-'highly unlikely' to 5-'highly likely'). The level of risk awareness was also indicated by an additional item measuring the coverage (yes or no) of accident injury insurance.

Attitudes (four items): respondents were asked to rate their attitudes and beliefs towards emergency preparedness on a 5-point Likert scale (ranging from 1-'strongly disagree' to 5-'strongly agree'). Example questions: 'Luck is more important than preparedness in emergencies'.

Community attachment (five items): respondents were asked to rate how closely they were attached to their community on a 5-point Likert scale (ranging from 1-'strongly disagree' to 5-'strongly agree'). Example statements: 'I'm willing to help my neighbour when they have troubles'.

Recognition of responsibility (one item): respondents were asked to judge whether volunteers should have some responsibility (yes or no) to respond to emergencies.

Self-efficacy (two items): respondents were asked to rate their capability to engage in an emergency response ('I am confident that I can cope with emergencies effectively') and mitigate risks ('I can always keep calm when I encounter emergencies') on a 5-point Likert scale (ranging from 1-'totally disagree' to 5-'totally agree').

Past experience of emergencies: respondents were asked whether they had ever experienced emergencies in the past (yes or no).

Exposure to awareness campaigns over the past year: respondents were asked whether they had received any emergency-related training in the past year (yes or no).

Behaviour in emergency preparedness (four items): respondents were asked to report their behaviours in relation to emergency preparedness on a 5-point Likert scale (ranging from 1-'totally disagree' to 5-'totally agree'). Example questions: 'I always take the initiative to participate in emergency training'.

\section{Quantitative analysis}

The two dependent variables (willingness to volunteer and participation in volunteering) were collapsed into two categories respectively, with 0 indicating 'unwilling' (score 1, 2 or 3) or 'no' and 1 indicating 'willing' (score 4 or 5 ) or 'yes'. 
The independent variables were transformed into categorical measurements for the purpose of statistical analyses due to a lack of evidence to support the assumptions of linear correlations. For the scales measuring knowledge, risk perception, attitudes, community attachment, self-efficacy and behaviour, a summed score was calculated before it was recoded into 1 'above average' and 0 'on/below average'.

$\chi^{2}$ tests were performed to determine the differences of the two dependent variables across different categories of the independent variables. The independent variables that showed statistical significance ( $p$ 0.05) were entered into a multivariate logistic regression model. The regression model was established to determine the effect size of each independent variable, adjusted for the influence of others. All statistical analyses were conducted using SPSS V.19.0. A $\mathrm{p}$ value (two-sided) less than 0.05 was considered to be statistically significant.

\section{In-depth interview}

Materials

Two semistructured interview guides were developed by the study team based on the study objectives. One semistructured interview guide was for volunteer organisation managers and officials and included questions regarding the emergency system construction, the operation of the emergency volunteering organisations, the status of and barriers to emergency volunteering. The other was for residents and included questions relating to the status and experience of residents' participation in emergency volunteering as well as the reasons for not participating.

\section{Sampling strategy and data collection}

The interviews were conducted in Heilongjiang province in October 2014. Ten residents and nine volunteer organisation managers and officials completed the interviews. Each interview took about $20-30 \mathrm{~min}$. The 10 residents were community members, who were selected from those who had finished our questionnaire survey. We contacted them through the community councils. Their interviews were administered face-to-face. The nine managers and officials were from volunteer organisations. Their interviews were conducted by telephone.

All interviews were digitally recorded, transcribed and thematically coded. The final sample size was determined by saturation of information when no new themes emerged.

\section{Qualitative analysis}

The interview data were analysed thematically. The coding framework was developed inductively from the data. The initial coding used open coding (codes derived directly from the data) and theoretical coding. The initial codes were then refined to produce a smaller set of themes. The coding framework was subject to continuing iterative revision during the course of analysis. ${ }^{31}$ Findings were discussed and approved by the study team.

\section{Data integration}

The categories emerging inductively from the interviews were compared with the findings of the questionnaire survey. Conclusions were made based on the consolidated results, which expanded the strength of each type of data to offer more robust evidence.

\section{Ethics approval}

The study was approved by the Medical Research Ethics Committee of Harbin Medical University. Participation in this study was completely voluntary. Written informed consent was obtained from each participant.

\section{Patient and public involvement}

Patients and members of the public were not involved in the design and conceptualisation of this study.

\section{RESULTS}

\section{Characteristics of respondents}

The respondents had an average age of $41.9(\mathrm{SD}=14.6)$ years; $56.2 \%$ were women; $58.0 \%$ resided in rural areas and $29.1 \%$ had obtained a university qualification. More than $52 \%$ of respondents had a monthly household income between $¥ 2000$ (\$300) and $¥ 4999$ (\$750) (table 1).

\section{Willingness to volunteer and participation in volunteering}

About $65.7 \%$ of respondents were willing to volunteer in emergency events, including $28.3 \%$ who expressed strong willingness. Only $7.7 \%$ of respondents were not willing to volunteer and $1.2 \%$ were strongly unwilling. About $24.3 \%$ of respondents had participated in emergencies as a volunteer.

\section{Factors associated with willingness to volunteer and participation in volunteering}

Willingness to volunteer varied by age, residency, educational attainment, knowledge about emergencies, risk perception, attitudes towards emergency preparedness, community attachment, recognition of responsibility, self-efficacy, preparedness behaviour, past experiences and injury insurance coverage. However, no significant differences in willingness to volunteer were found across gender, income and exposure to emergency awareness campaigns ( $\mathrm{p}>0.05$, table 1$)$.

Participation in volunteering varied by gender, age, residency, educational attainment, knowledge about emergencies, community attachment, recognition of responsibility, preparedness behaviour, past experiences, injury insurance coverage and exposure to emergency awareness campaigns. However, income, risk perception, attitudes towards emergency preparedness and self-efficacy were not found to be associated with participation in volunteering $(\mathrm{p}>0.05$, table 1$)$.

The two multivariate logistic regression models confirmed the results of the $\chi^{2}$ tests. The respondents who were older, resided in rural areas and had a university qualification were more likely to be willing to volunteer in 
Table 1 Characteristics of respondents and their willingness to volunteer and participation in volunteering $(n=2686)$

\begin{tabular}{|c|c|c|c|c|c|c|c|}
\hline Characteristics & Respondents (n (\%)) & $\begin{array}{l}\text { Willingness } \\
(\mathrm{n}(\%))\end{array}$ & $\chi^{2}$ & $P$ values & $\begin{array}{l}\text { Participation } \\
\text { (n (\%)) }\end{array}$ & $\chi^{2}$ & $P$ values \\
\hline \multicolumn{3}{|l|}{ Gender } & 3.374 & 0.066 & & 18.403 & 0.000 \\
\hline Male & $1177(43.8)$ & $751(63.8)$ & & & $333(28.3)$ & & \\
\hline Female & 1509 (56.2) & $1014(67.2)$ & & & $319(21.1)$ & & \\
\hline \multicolumn{2}{|l|}{ Age (years) } & & 19.168 & 0.000 & & 11.328 & 0.003 \\
\hline$<35$ & $910(33.9)$ & $550(60.4)$ & & & $250(27.5 \%)$ & & \\
\hline $35-55$ & $1265(47.1)$ & $852(67.4)$ & & & $302(23.9 \%)$ & & \\
\hline $55+$ & $511(19.0)$ & $363(71.0)$ & & & $100(19.6 \%)$ & & \\
\hline \multicolumn{2}{|l|}{ Residency } & & 12.292 & 0.000 & & 3.869 & 0.049 \\
\hline Rural & $1559(58.0)$ & $1067(68.4)$ & & & $400(25.7)$ & & \\
\hline Urban & $1127(42.0)$ & $698(61.9)$ & & & $252(22.4)$ & & \\
\hline \multicolumn{2}{|l|}{ Educational attainment } & & 6.254 & 0.044 & & 19.647 & 0.000 \\
\hline$\leq$ Juniorhigh school & $1260(46.9)$ & $830(65.9)$ & & & $262(20.8)$ & & \\
\hline Senior high school & $644(24.0)$ & $400(62.1)$ & & & $160(24.8)$ & & \\
\hline University & $782(29.1)$ & $535(68.4)$ & & & $230(29.4)$ & & \\
\hline \multicolumn{2}{|c|}{ Household monthly income ( $¥ / \$)$} & & 1.189 & 0.552 & & 1.603 & 0.449 \\
\hline 0-1999/0-300 & $853(31.8)$ & $573(67.2)$ & & & $217(25.4)$ & & \\
\hline $2000-4999 / 300-750$ & $1409(52.4)$ & $916(65.0)$ & & & $328(23.3)$ & & \\
\hline $5000+/ 750+$ & $424(15.8)$ & $276(65.1)$ & & & $107(25.2)$ & & \\
\hline \multicolumn{2}{|c|}{ Knowledge about emergencies } & & 53.966 & 0.000 & & 35.438 & 0.000 \\
\hline On/below average & $1083(40.3)$ & $623(57.5)$ & & & $242(19.0)$ & & \\
\hline Above average & $1603(59.7)$ & $1142(71.2)$ & & & $410(28.9)$ & & \\
\hline \multicolumn{2}{|l|}{ Risk perception } & & 10.137 & 0.001 & & 2.725 & 0.099 \\
\hline On/below average & $1420(52.9)$ & $894(63.0)$ & & & $363(25.6)$ & & \\
\hline Above average & $1266(47.1)$ & $871(68.8)$ & & & $289(22.8)$ & & \\
\hline \multicolumn{3}{|c|}{ Attitudes towards emergency preparedness } & 56.259 & 0.000 & & 0.903 & 0.342 \\
\hline On/below average & $1370(51.0)$ & $808(59.0)$ & & & $322(23.5)$ & & \\
\hline Above average & $1316(49.0)$ & $957(72.7)$ & & & $330(25.1)$ & & \\
\hline \multicolumn{2}{|l|}{ Community attachment } & & 74.360 & 0.000 & & 31.146 & 0.000 \\
\hline On/below average & $1522(56.7)$ & $895(58.8)$ & & & $308(20.2)$ & & \\
\hline Above average & $1164(43.3)$ & $870(74.7)$ & & & $344(29.6)$ & & \\
\hline \multicolumn{2}{|c|}{ Recognition of responsibility } & & 36.808 & 0.000 & & 13.025 & 0.000 \\
\hline Yes & $372(13.8)$ & $296(79.6)$ & & & 118 (31.72) & & \\
\hline No & $2314(86.2)$ & $1469(63.5)$ & & & $534(23.08)$ & & \\
\hline \multicolumn{2}{|l|}{ Self-efficacy } & & 54.824 & 0.000 & & 0.888 & 0.346 \\
\hline On/below average & $1456(54.2)$ & $866(59.5)$ & & & $343(23.56)$ & & \\
\hline Above average & $1230(45.8)$ & $899(73.1)$ & & & $309(25.12)$ & & \\
\hline \multicolumn{2}{|l|}{ Preparedness behaviour } & & 91.289 & 0.000 & & 29.143 & 0.000 \\
\hline On/below average & $1530(57.0)$ & $889(58.1)$ & & & $312(20.39)$ & & \\
\hline Above average & $1156(43.0)$ & $876(75.8)$ & & & $340(29.41)$ & & \\
\hline \multicolumn{2}{|c|}{ Past experience of emergencies } & & 32.690 & 0.000 & & 5.901 & 0.015 \\
\hline Yes & $580(21.6)$ & $439(75.7)$ & & & $163(28.10)$ & & \\
\hline No & $2106(78.4)$ & $1326(63.0)$ & & & $489(23.22)$ & & \\
\hline \multicolumn{3}{|c|}{ Exposure to awareness campaigns over the past year } & 2.988 & 0.084 & & 95.869 & 0.000 \\
\hline Yes & $657(24.5)$ & $450(68.5)$ & & & $253(38.51)$ & & \\
\hline
\end{tabular}


Table 1 Continued

\begin{tabular}{|c|c|c|c|c|c|c|c|}
\hline Characteristics & Respondents (n (\%)) & $\begin{array}{l}\text { Willingness } \\
\text { (n (\%)) }\end{array}$ & $\chi^{2}$ & $P$ values & $\begin{array}{l}\text { Participation } \\
\text { (n (\%)) }\end{array}$ & $\chi^{2}$ & $P$ values \\
\hline No & 2029 (75.5) & $1315(64.8)$ & & & 399 (19.66) & & \\
\hline Injury insurance coverage & & & 11.830 & 0.001 & & 51.285 & 0.000 \\
\hline Yes & 789 (29.4) & 557 (70.6) & & & 264 (33.46) & & \\
\hline No & $1897(70.6)$ & $1208(63.7)$ & & & $388(20.45)$ & & \\
\hline
\end{tabular}

emergencies. Willingness to volunteer was also positively associated with better knowledge about emergencies, higher risk perception, more positive attitudes towards emergency preparedness, past experience of emergencies, stronger community attachment, higher recognition of responsibility, higher self-efficacy, preparedness behaviour and injury insurance coverage (table 2).

The respondents who were male, resided in rural areas and had a senior high school or university qualification were more likely to participate in emergency volunteering. Participation in volunteering was also positively associated with stronger community attachment, higher recognition of responsibility, preparedness behaviour, injury insurance coverage and exposure to awareness campaigns (table 2).

\section{Gap between willingness to volunteer and participation in volunteering}

Two main themes were identified from the qualitative analysis process: 'policy environment' and 'organisational management'. The interviews revealed that an inappropriate policy environment and incomplete volunteer organisational management were major barriers for converting willingness into actions. Table 3 illustrates the key concepts emerging from the interviews.

Policy environment refers to the related policies, laws, regulations and coordination mechanisms on emergency responses. The interviewees agreed that there was a shortage of unified national laws and regulations in relation to volunteer services. Local regulations were inconsistent across regions. In addition, no reliable government funding was allocated to support the organisation of emergency volunteering. The Wenchuan earthquake demonstrated the failure of the national emergency response system to integrate volunteer organisations and spontaneous volunteers into rescue and recovery efforts.

Inappropriate management of volunteers, including volunteer recruitment, training, protection and incentive mechanisms, contributed to the limited willingness of the public to volunteer and participation in emergency volunteering. The interviewees reported a lack of an intermediary recruitment platform for volunteer organisations and communities. The public was not well-informed of the channels by which to participate in volunteering activities. The incentive mechanisms (such as reward systems) and protection mechanisms (such as insurance coverage) fell behind the needs of volunteers, restricting their participation in emergency volunteering.
In addition, emergency volunteering had not become a culture commonly shared by society.

In summary, based on the findings from the questionnaire survey and the in-depth interviews, public willingness to volunteer and participation in emergency volunteering are shaped by factors from the individual, community and institutional perspectives (figure 1).

\section{DISCUSSION}

Non-professional rescue workers and volunteers play a vital role in an emergency response system. ${ }^{32}$ Successful rescue operations in emergencies depend on coordinated efforts by a wide range of responders. ${ }^{33}$ In this study, we found a relatively high level of willingness to volunteer: more than $65 \%$ of respondents were willing to volunteer in emergencies. However, only a small percentage $(24.3 \%)$ of respondents had participated in emergency volunteering. Willingness to volunteer and participation in volunteering are determined by many factors, including those at the individual level, community level as well as those at the institutional level. The findings of this study support the theory of rational action. ${ }^{20}$

\section{Individual factors}

In this study, we found that people with a better knowledge of emergencies are more likely to be willing to volunteer. Indeed, knowledge and skills are deemed as key factors in influencing human behaviours in several behavioural investigations. ${ }^{34}$

Training and education is perhaps the most commonly used strategy for improving knowledge and awareness. Education helps shape people's consciousness, cognition and behaviour. ${ }^{35}$ Evidence shows that education is the most consistent and strongest determinant of volunteering participation, ${ }^{36}$ which is consistent with our findings. Exposure to emergency awareness campaigns appeared to be a significant factor influencing volunteering participation. But only $24.5 \%$ of respondents had been exposed to emergency awareness campaigns over the past year. This level is very low compared with Japan where an 'education for all' system exists, integrating emergency education (for disaster prevention and mitigation) into school education and community activities. ${ }^{9}$ Unlike in many developed countries, volunteer training has not been integrated into the national emergency rescue system in China. ${ }^{24}$ In the USA, for example, the CERT programme was established in 1985, recognising 
Table 2 Factors associated with willingness to volunteer and participation in volunteering - findings from multivariate logistic regression analysis

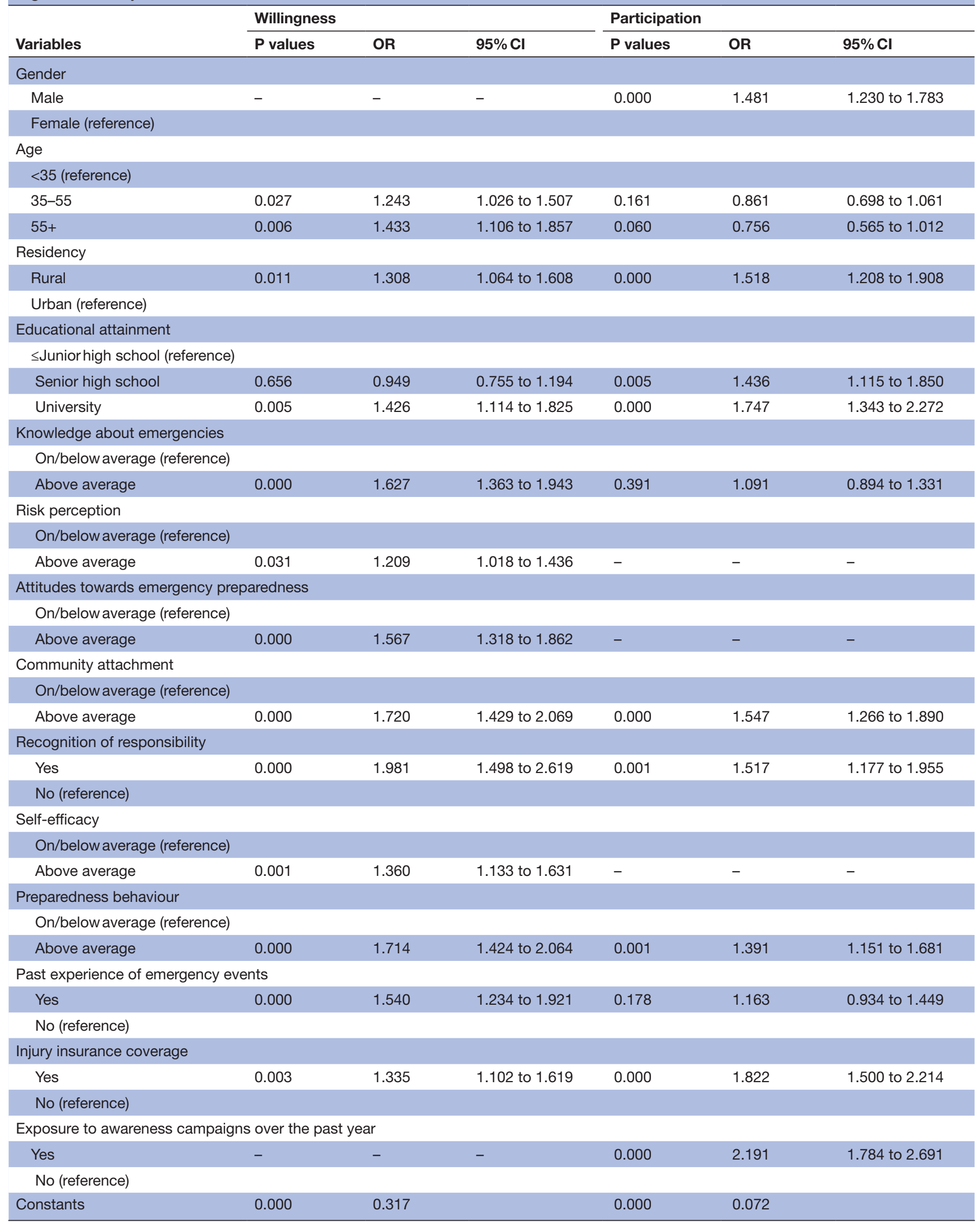


Table 3 Overarching categories and key concepts emerging from qualitative analyses of the interviews

\begin{tabular}{ll}
\hline Category & Concept \\
\hline Policy environment & Related policies \\
&
\end{tabular}

Related Law

Representative quote(s)

'Honestly speaking, it is very hard to maintain normal operations of volunteer organisations with only a small amount of funds being given by the government.' (volunteer organisation manager)

'As far as I know, there are no unified laws and regulations for volunteer services throughout the country, and the laws and systems set up by the local governments vary.' (official)

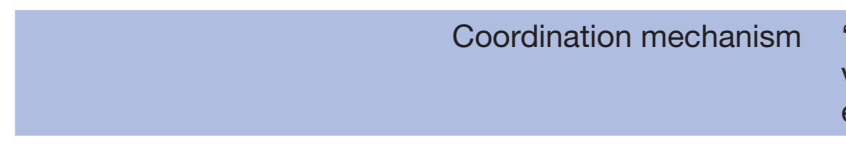

Organisational management Volunteer recruitment

Incentive mechanism
Emergency training

'Because of a lack of effective coordination, both spontaneous volunteers and organised volunteers failed to play their role in many emergency rescue efforts and they instead caused chaos.' (official)

'I have lived in the area for years, but have never heard about volunteer recruitment, I don't know where to go to volunteer.' (resident)

'I don't have any first aid skills and do not know where to get the training. As for our communities, it seems that there has never been any organisation which provides emergency education and training. So I do not think I have the ability to be an emergency volunteer.' (resident)

Protection mechanism 'Emergency rescue is risky, and I don't have insurance. If I volunteer, I'm not sure if there are organisations or agencies that would provide me with risk-reduction protection.' (resident)

'In our country, volunteers generally are given a few honourable rewards, such as certificates and honorary titles. There is a lack of incentives related to their benefits. Also, there is a lack of a volunteering culture in this society.' (volunteer organisation manager)

the fact that disaster survivors are likely to be on their own at the early stage of a disaster and they need to be prepared to help themselves. ${ }^{16}$ Germany, Australia and some other countries have also established an emergency training system focusing on emergency volunteering services. $^{2} 1537$

Better knowledge can improve risk perception and self-efficacy, which can strengthen willingness to volunteer. ${ }^{38} 39$ In this study, we found that increased risk perception, more positive attitudes towards emergency preparedness and injury insurance coverage are significant predictors of willingness to volunteer. Injury insurance coverage is also a strong predictor of volunteering participation. Risk perception and injury insurance coverage are an indication of risk awareness. We found that the respondents covered by injury insurance have a higher ratio of participation in emergency volunteering than those without insurance. In Japan and Germany, emergency volunteering services are encouraged through a sound volunteer risk management system, such as volunteer insurance programmes..$^{15} 1718$ In Germany, the government has a statutory responsibility to purchase insurance for volunteers. ${ }^{15}$

Respondents who report high levels of confidence and a perceived ability to respond are more likely to participate in volunteering. We found that self-efficacy is a significant predictor of willingness to volunteer, and emergency preparedness behaviours influence both willingness to volunteer and participation in volunteering. These findings are consistent with previous studies. Wang and colleagues found that self-efficacy has a strong impact on behaviours and behaviour intentions in challenging environments. ${ }^{40}$ Emergency preparedness training can result in knowledge gains and shifts attitudes towards volunteering. ${ }^{41}$ Fothergill and colleagues found that nurses have higher willingness and participation in emergency volunteering services, partly because nurses are professionally trained and adequately prepared. ${ }^{42}$

We found that past experience of emergencies is associated with higher willingness to volunteer. This is perhaps because these people have developed a better understanding of the need for volunteering services. Emergency experience may prompt people to become more proactive in acquiring the knowledge and skills associated with an emergency response, ${ }^{43}$ boosting their confidence to participate in volunteering services.

In this study, older age was found to be associated with higher willingness to volunteer in emergency events. Previous studies identified 35-55 years as the most active age for volunteering. ${ }^{36}$ Smith argues that this may be due to the rising socioeconomic status of middle-aged people. ${ }^{36}$ Lee and colleagues point out that social and family commitment may be a factor shaping people's decision to volunteer. ${ }^{35}$ Older people may be more experienced and confident to participate in volunteering. The results of this study showed that participation in emergency volunteering is higher for men, which is consistent with the findings of a previous study. ${ }^{36}$ 


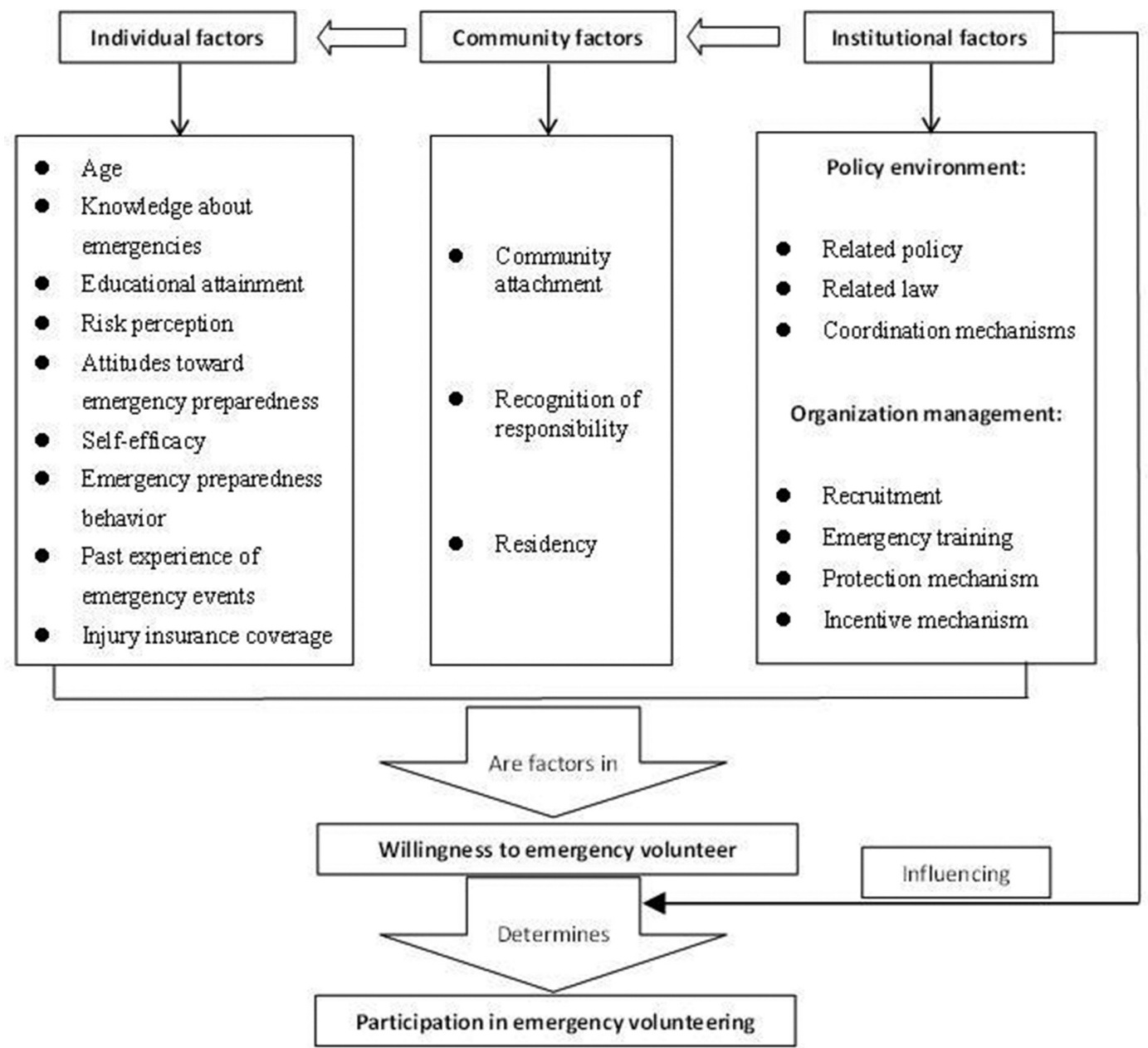

Figure 1 Factors associated with willingness to volunteer and participation in volunteering shows that willingness to volunteer and participation in volunteering are determined by many factors, including those at the individual level (age, knowledge about emergencies, educational attainment and so on), community level (community attachment, recognition of responsibility and residency) and institutional level (policy environment and organisation management). Willingness to emergency volunteer determines participation in emergency volunteering; also, institutional factors influence participation in emergency volunteering directly.

\section{Community factors}

Social capital can foster trust and enforce reciprocal behaviours in a group. ${ }^{12} 30$ We found that community attachment is a significant predictor of volunteering willingness and participation. Previous studies conducted in several western countries showed that people who have a strong consciousness of neighbourhood and a sense of belonging to community are most likely to participate in community volunteering activities. ${ }^{44} 45$ Social relations based on trust and solidarity can encourage emergency volunteering. ${ }^{30} 44$

We found that rural residents are more likely to be willing to volunteer and participate in volunteering than their urban counterparts. It has been widely accepted that rural residents have a stronger bond and sense of community than their urban counterparts. ${ }^{4446}$ This is no exception in China. Studies have found that a strong local concentration of network ties is more common in people with lower social status (eg, people with lower levels of income and education). Naturally, rural residents in China have a stronger sense of community and are more inclined to help each other. ${ }^{48}$ The urban overload hypothesis speculates that urban residents are often exposed to many events; so they are inclined to be immune to a mass of information. ${ }^{49}$

In this study, we found that recognition of responsibility is a significant predictor of willingness to volunteer and participation in volunteering. Recognition of responsibility refers to the individual's understanding, emotion and belief of social responsibility as well as their subconscious attitude to assume obligation and responsibility, which can help volunteering to become a normalised activity. ${ }^{50}$ However, a low level of recognition of responsibility $(13.8 \%)$ was demonstrated among the study participants. In the UK, most emergency volunteers engage in volunteering activities 'just to give something back to the community'. ${ }^{44}$ Some western countries even use legislation tools to mandate community responsibilities. In Norway, for example, the 'Fire and Explosion Prevention Act' stipulates that the public has a duty and obligation 
to assist in fire and rescue services when required by the on-scene commander. ${ }^{24}$

\section{Institutional factors}

Previous studies suggest that the model of volunteer management consists of four components: leadership, integration processes, resources commitment and relative autonomy of volunteers. ${ }^{37}$

The participants of this study believed that the policy environment is critical for promoting emergency volunteering and that government-supported volunteer activities are more effective. ${ }^{51}$ In the USA, the encouragement of volunteering has long been public policy. The Serve America Act of 2009 presented the most dramatic expansion of the size and scope of policies supporting volunteering. The act, on the one hand, has increased the quantity of volunteers nationwide by providing inducements (such as an education award or income); on the other hand, it has strengthened the development of volunteering organisations through the provision of funds. ${ }^{22}$ Analogously, Australia and New Zealand provide strong financial support to their emergency volunteering. ${ }^{37}$

Volunteering organisational management was considered by our interviewees to be another institutional factor influencing participation in emergency volunteering. The contributions of volunteers, especially those from unorganised volunteers, are not always positive in emergency events. Their desire to help may not align well with the planned strategy of rescue efforts. ${ }^{24}$ Drill exercises may offer a platform for the better coordination of unorganised volunteers. ${ }^{24}{ }^{37}$ There is also a need to develop a transparent certification and reward system, attracting and recognising volunteer efforts. ${ }^{52}$

\section{Strengths and limitations}

This study adopted a mixed methods approach, involving a questionnaire survey and in-depth interviews. The findings from the two methods complement and support each other. Factors associated with willingness to volunteer and participation in emergency volunteering were explored from individual, community and institutional perspectives.

The questionnaires were administered through faceto-face interviews. Such an approach has the potential to result in response bias. However, the risk is minimal when the questions are deemed non-sensitive by the respondents and the interviewers are strangers to the respondents. We also trained the interviewers to avoid suggestive questioning.

The concept of 'emergency events' adopted in this study was general and covered a broad range of events including natural disaster, human-made accidents, public health emergencies and social unrest. This may lead to vague or uncertain answers from some respondents. Self-reported willingness to volunteer may vary in different scenarios. ${ }^{22}$ Scenario-based studies should be considered in the future for a better understanding of the findings. This study was conducted in Heilongjiang, which may not be representative of the entire country of China. Caution need to be taken when generalising the findings. The cross-sectional design of this study does not allow causal conclusions to be drawn.

\section{CONCLUSION}

A relatively high level of willingness to volunteer in emergency events is evident in northern China. But willingness has not effectively translated into volunteering actions. People with a better knowledge of emergencies are more likely to be willing to volunteer because they have better risk perceptions and are more confident to participate in volunteering. However, low levels of recognition of responsibility and community attachment may demotivate people to participate in emergency volunteering. Inappropriate institutional environments may also impose serious barriers, jeopardising the willingness of people to volunteer and their contribution to volunteering services. Future efforts should be made to convert volunteering willingness into effective contributions to the emergency response system. This can be done through improving the organised efforts of volunteers by implementing policies, regulations, coordination mechanisms and volunteer training and support.

Acknowledgements The authors are grateful for the support of local officials from the sampled municipalities. They thank all of the postgraduate students who collected the data and all of the participants for their time and insight.

Contributors MS participated in the design of the research, conducted the survey and data analyses and drafted the manuscript. YH and QHW took overall responsibility for the study design, coordination of the survey, development of the analysis framework and writing of the manuscript. WX, LG, ZK, NN, CL, HS, MJ, LL, $\mathrm{YL}, \mathrm{YC}$ and $\mathrm{XZ}$ participated in the design of the research, organised and conducted the survey. CJL supervised the data analyses, interpreted the results and revised the manuscript. JF, QW and MY participated in the literature review and data collection. MS, WX and LG contributed equally.

Funding This study was funded by the National Natural Scientific Fund of China $(71173064,71473065)$ and the Ministry of Health Public Benefit Fund for Health Sector (201002028).

Competing interests None declared.

Patient consent Not required.

Provenance and peer review Not commissioned; externally peer reviewed.

Open access This is an open access article distributed in accordance with the Creative Commons Attribution Non Commercial (CC BY-NC 4.0) license, which permits others to distribute, remix, adapt, build upon this work non-commercially, and license their derivative works on different terms, provided the original work is properly cited, appropriate credit is given, any changes made indicated, and the use is non-commercial. See:@http://creativecommons.org/licenses/by-nc/4.0/.

\section{REFERENCES}

1. Bachner G, Seebauer S, Pfurtscheller C, et al. Assessing the benefits of organized voluntary emergency services: Concepts and evidence from flood protection in Austria. Disaster Prevention and Management 2016;25:1-17.

2. Oklahoma department of civil emergency management after action report: Alfred P. Murrah federal building bombing. https://www.ok. gov/OEM/documents/Bombing\%20After\%20Action\%20Report.pdf (accessed 20 Aug 2017).

3. Whittaker J, McLennan B, Handmer J. A review of informal volunteerism in emergencies and disasters: Definition, opportunities and challenges. International Journal of Disaster Risk Reduction 2015;13:358-68. 
4. Orloff L. Managing spontaneous community volunteers in disasters: a field manual: Crc Press, 2011.

5. European Volunteer Centre. Voluntary Action Italy: facts and figures. http://www.kansalaisareena.fi/Voluntary\%20Action\%20ltaly.pdf (accessed 28 Sep 2017).

6. The role of volunteers in disaster response. http://www.volunteerlink. net/datafiles/D061.pdf (accessed 25 Sep 2017).

7. Community emergency response team. https://www.ready.gov/ community-emergency-response-team (accessed 28 Sep 2017).

8. Zhang ZR. Summarize lessons from disaster-Japanese training. China Emergency Management 2010;2:52-4.

9. Yuan Y, Zhu W, Chen G. Volunteer's organization and management in wenchuan earthquake: problems and countermeasures. China Nonprofit Review 2008;2:276-82.

10. The state council information office of the People's Republic of China. China's actions for disaster prevention and reduction. http:// www.scio.gov.cn/zfbps/ndhf/2009/Document/847130/847130.html (accessed 25 Jan 2017).

11. Cowlishaw S, Birch A, McLennan J, et al. Antecedents and Outcomes of Volunteer Work-Family Conflict and Facilitation in Australia. Appl Psychol 2014;63:168-89.

12. Pfurtscheller $C$, Brucker A, Seebauer S. Prepared for the future? Evaluating the costs and benefits of voluntary work for natural disaster management under a changing climate - data on recent flood events, stakeholder needs and policy applications. European Geosciences Union General Assembly 2014

13. Song YC. Reflections on Japan 's emergency volunteer service mechanism. Chin Legal System and Society 2014;27.

14. Medical Reserve Corps. About the Medical Reserve Corps. https:// mrc.hhs.gov/pageviewfldr/About (accessed 25 Aug 2017).

15. Lin XW. Characteristics and enlightenment of volunteer system in German emergency rescue. Chin Journal of Liaoning Administration College 2010;12:9-10.

16. FEMA. Community emergency response team: basic training participant manual. https://www.fema.gov/media-library-data/ 1448917365279-3a7949605bd9e03633af2473a5741aa9/Section_0_ PM Combined.pdf (accessed 16 March 2017).

17. The Xinhua News Agency. "volunteer first year" of Japan since the Hanshin earthquake. http://news.xinhuanet.com/mrdx/2008-06/04/ content_8312305.html (accessed 5 Feb 2017).

18. How does Japan organize volunteers in an orderly manner to relieve a disaster? http://world.people.com.cn/GB/14549/7334918.html (accessed 9 Feb 2017).

19. Guan RH. The role of volunteers in a disaster early warning management system. China Safety 2010;31:1-4.

20. Duang YT, Jiang GR. Review of theory of rational action. Adv Psychol Sci 2008;16:315-20.

21. Finkelstein MA, Penner LA, Brannick MT. Motive, role identity, and prosocial personality as predictors of volunteer activity. Soc Behav Pers 2005:33:403-18.

22. Blau G, Chapman S, Gibson G, et al. Exploring the importance of different items as reasons for leaving emergency medical services between fully compensated, partially compensated, and noncompensated/volunteer samples. J Allied Health 2011;40:e33-7.

23. Barnett DJ, Thompson CB, Errett NA, et al. Determinants of emergency response willingness in the local public health workforce by jurisdictional and scenario patterns: a cross-sectional survey. BMC Public Health 2012;12:164.

24. Nesbit R, Brudney JL. Projections and policies for volunteer programs: the implications of the serve america act for volunteer diversity and management. Nonprofit Management and Leadership 2013;24:3-21.

25. Rosychuk RJ, Bailey T, Haines C, et al. Willingness to volunteer during an influenza pandemic: perspectives from students and staff at a large Canadian university. Influenza Other Respir Viruses 2008:2:71-9.

26. Skar M, Sydnes M, Sydnes AK. Integrating unorganized volunteers in emergency response management. International Journal of Emergency Services 2016;5:52-65.

27. Heilongjiang municipal GDP and per capita GDP ranking. 2015 http://www.phbang.cn/finance/data/152416.html (accessed 19 Oct 2016).
28. Enders J. Measuring community awareness and preparedness for emergencies. Australian Journal of Emergency Management 2001;16:52-8.

29. Zhang AQ. Self-efficacy and organization networking. Organizational Behavior. 126. Beijing, BJ: China Machine Press, 2013.

30. Catts R, Chamings D. Recognising current competencies of volunteers in emergency service organisations. J Workplace Learn 2006;18:451-63.

31. Braun V, Clarke V. Using thematic analysis in psychology. Qual Res Psychol 2006;3:77-101.

32. Anon. CISCO: Cisco and the red cross launch global volunteer initiative; just in time for national volunteer week, collaboration creates largest corporate disaster response volunteer program in red cross history. M2 Presswire 2010.

33. Liu C, Robinson P. Better organisation of volunteers in disaster settings is needed: lessons for all from China. Aust N Z J Public Health 2013;37:595-6.

34. Vaughan E, Tinker T. Effective health risk communication about pandemic influenza for vulnerable populations. Am J Public Health 2009;99 Suppl 2:S324-S332.

35. Lee S, Saito T, Takahashi M, et al. Volunteer participation among older adults in Japan: an analysis of the determinants of participation and reasons for non-participation. Arch Gerontol Geriatr 2008;47:173-87.

36. Smith $\mathrm{DH}$. Determinants of voluntary association participation and volunteering: a literature review. Nonprofit Volunt Sect $Q$ 1994;23:243-63.

37. O'Meara P, Tourle V, Rae J. Factors influencing the successful integration of ambulance volunteers and first responders into ambulance services. Health Soc Care Community 2012;20:488-96.

38. Bandura A. Self-efficacy: the exercise of control. Journal of Cognitive Psychotherapy 1997;604:158-66.

39. Knuth D, Kehl D, Hulse L, et al. Risk perception, experience, and objective risk: a cross-national study with European emergency survivors. Risk Anal 2014;34:1286-98.

40. Wang JW, Wei CN, Harada K, et al. Applying the social cognitive perspective to volunteer intention in China: the mediating roles of self-efficacy and motivation. Health Promot Int 2011;26:177-87.

41. Qureshi KA, Gershon RR, Merrill JA, et al. Effectiveness of an emergency preparedness training program for public health nurses in New York City. Fam Community Health 2004;27:242-9.

42. Fothergill A, Palumbo MV, Rambur B, et al. The volunteer potential of inactive nurses for disaster preparedness. Public Health Nurs 2005;22:414-21.

43. Xu W, Hao Y, Wu Q, et al. Community preparedness for emergency: a cross-sectional survey of residents in Heilongjiang of China. BMJ Open 2015;5:e008479.

44. Roberts A, Nimegeer A, Farmer J, et al. The experience of community first responders in co-producing rural health care: in the liminal gap between citizen and professional. BMC Health Serv Res 2014;14:460.

45. Taniguchi $\mathrm{H}$, Marshall GA. The effects of social trust and institutional trust on formal volunteering and charitable giving in Japan. VOLUNTAS: International Journal of Voluntary and Nonprofit Organizations 2014;25:150-75.

46. Sonderskov KM. Does generalized social trust lead to associational membership? unravelling a bowl of well-tossed spaghetti. Eur Sociol Rev 2011;27:419-34

47. Hofferth SL, Iceland J. Social capital in rural and urban communities. Rural Sociol 1998;63:574-98.

48. Beggs JJ, Hurlbert JS, Haines VA. Community attachment in a rural setting: a refinement and empirical test of the systemic model. Rural Sociol 1996;61:407-26.

49. Elliot A, Hou YB. Social psychology. 5th edn: China Light Industry Press, 2005:332-84.

50. Schlenker BR, Britt TW, Pennington J, et al. The triangle model of responsibility. Psychol Rev 1994;101:632-52.

51. Perlstadt $H$, Kozak LJ. Emergency medical services in small communities. J Community Health 1977;2:178-88.

52. Palaz S, Boz S. Factors influencing college graduate adults to provide volunteer service in different organizations. Ballkesir Üniversitesi Sosyal Bilimler Dergisi 2008;11:95-106. 